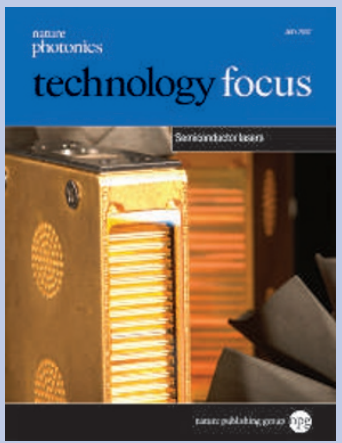

Cover image

Dilas's 20-element laser-diode stack has sufficient output power for applications in materials processing.

Business News p390

EDITOR: OLIVER GRAYDON

ASSOCIATE EDITORS: DAVID GEVAUX, AMBER JENKINS, RACHEL PEI CHIN WON

PRODUCTION EDITORS: SIMON GERRARD, CHRIS GILLOCH

COPY EDITOR: ANNA DEMMING

ART EDITOR: KAREN MOORE

\title{
Filling the gaps
}

MARKET ANALYSIS

379 Acquisitions galore in the diode sector

Oliver Graydon applications, ranging from data storage and telecommunications through to materials processing. Indeed our two Industry Perspective articles on p385 and p387 are perfect examples of just how far the technology has come and what a powerful enabling platform it is now.

The first describes how high-output monolithic arrays of semiconductor lasers look set to bring big benefits to the printing industry, enabling the construction of laser print heads that offer unprecedented levels of quality and speed.

The second discusses how, when a large number of emitters are stacked and multiplexed, they can provide convenient sources in the kilowatt regime for surfacetreatment tasks, such as hardening and annealing, for example.

Needless to say the strategic importance of having this kind of technology in-house has been recognized by many major laser firms, and in our Market Analysis piece on p379 we describe the latest spate of acquisitions and investments in the sector by some well-known names in photonics.

Despite the impressive progress that has been made in the field over the years, it is clear that there are still some significant challenges ahead. In particular, although the wavelength of operation of devices has steadily expanded to span from the UV to the mid-infrared, there are important wavelength gaps where semiconductor sources of light are urgently required. For instance, in the visible region, high-performance semiconductor sources of green light are still lacking. If these could be made, they could be combined with red and blue laser diodes to open the door to bright white-light generation, colour mixing and laser-based displays and televisions. At the same time, semiconductor lasers that emit terahertz radiation would help inspire the development of compact and practical instruments for security screening and biomedical imaging. 